\title{
PENGEMBANGAN DESAIN SARANA MEMASAK MAKANAN RINGAN PORTABEL
}

\author{
Dita Andansari \\ Staf Pengajar Program Studi Desain Produk, Jurusan Desain \\ Politeknik Negeri Samarinda \\ Hayde Starizky Dirgatama Girsang \\ Mahasiswa Program Studi Desain Produk, Jurusan Desain \\ Politeknik Negeri Samarinda
}

\begin{abstract}
ABSTRAK
Piknik adalah salah satu bentuk refresing yang murah meriah yang bisa dikerjakan bersamasama keluarga atau bersama teman-teman untuk berlibur maupun bersantai. Kita bisa beristirahat sejenak dari sibuknya rutinitas sehari-hari yang menjenuhkan otak. Kegiatan piknik identik dengan acara makan-makan atau sekedar ngemil sambil mengobrol dengan keluarga atau teman-teman yang lain. Makanan yang sering dipilih seperti kentang goreng, nugget, popcorn untuk sekedar ngemil. Biasanya lebih mudah untuk membeli namun kita tidak mengetahui kebersihan makanan yang kita beli ataupun apa saja zat yang terkandung di makanan tersebut selain itu ketika makanan tersebut habis namun kegiatan masih berlangsung, terkadang malas untuk membelinya lagi. Berdasarkan fakta diatas maka diperlukan sebuah rancangan Sarana Memasak Makanan Ringan yang bersifat ringkas yang bisa memenuhi kebutuhan memasak saat bertamasya. Diharapkan desain sarana memasak ini dapat menjadi solusi akan kebutuhan memasak pada saat berlibur dan bertamasya.
\end{abstract}

Kata kunci: Kompor piknik, kompor portabel

\begin{abstract}
Picnic is one refresing a cheap form that can be shared and loved ones or with friends for a vacation and relax. We can take a break from the busy daily routine that saturate the brain. Picnic activities synonymous with the feast or just snacking and chatting with family or friends to another. Food was often chosen as fries, nuggets, popcorn for a snack. Usually it is easier to buy, but we do not know the cleanliness of the food we buy or what the substances contained in these foods than that when the food runs out, but activity is still ongoing, sometimes lazy to buy it again. , Based on the above it would require a draft Means of Cooking Light that is compact that can meet the needs of cooking time sightseeing. This cooking tool design is expected to be a solution would need to cook in while on vacation and sightseeing.
\end{abstract}

Keywords: picnic stove, portable stove 
Vol. 3, No. 2, April 2016

\section{Pendahuluan}

Rekreasi adalah kegiatan yang menyehatkan pada aspek sosial, fisik dan mental. Jay B. Nash memberikan gambaran bahwa aktivitas rekreasi adalah pelengkap dari kerja, oleh karena itu rekreasi adalah kebutuhan semua orang. Dengan demikian, penekanan dari aktivitas rekreasi adalah dalam nuansa "menciptakan kembali” (recreation) orang tersebut, ada upaya revitalisasi jiwa dan tubuh yang terwujud karena 'menjauh' dari kegiatan rutin dan kondisi yang menekan dalam kehidupan sehari-hari.

Piknik adalah salah satu bentuk refresing yang murah meriah yang bisa dikerjakan bersama-sama keluarga atau bersama teman-teman untuk berlibur maupun bersantai. Kegiatan piknik identik dengan acara makan-makan atau sekedar ngemil sambil mengobrol dengan keluarga atau teman-teman. Makanan yang sering dipilih adalah kentang goreng, nugget, popcorn untuk sekedar ngemil..

Banyak sekali produk yang bisa membuat makanan tersebut, namun masih memiliki kekurangan untuk digunakan pada saat melakukan aktifitas di luar rumah atau outdoor. Seperti produk tersebut harus menggunakan listrik untuk melakukan pengoprasian memasak. Banyaknya komponen yang harus dibawa seperti, panci kompor dan perkakas masak lainnya dengan setiap produk memiliki dimensi yang cukup besar.

Dengan adanya permasalahan di atas, diperlukan suatu rancangan produk sarana memasak makanan ringan portable yang nyaman dibawa, mudah dibuka saat dalam keadaan terkunci juga nyaan di pegang karena tidak memiliki sudut tajam.

\section{Metode Perancangan}

Dalam mendesain produk ini dilakukan beberapa tahapan-tahapan, yaitu:

1. Perumusan Masalah. Dengan mendata permasalahan apa yang ada pada produk yang ada saat ini..

2. Tinjauan Pustaka. Yaitu melakukan Studi eksisting yang terdiri dari definisi eksisting beserta jenis dan fasilitas yang diperlukan. Teori segmentasi meliputi segmentasi geografis, segmentasi demografis, segmentasi psikografis, segmentasi prilaku dan segmentasi manfaat. Teori ergonomi dan antropometri untuk pengguna. Teori sistem yang digunakan, Sistem kuncian, sistem sambungan dan sistem finishing. Teori bentuk yang digunakan berdasarkan pendekatan bentuk gaya desain. Teori warna yang akan digunakan berdasarkan psikologi warna.

3. Analisis dan Spesifikasi Desain, meliputi Analisis pasar, studi aktifitas dan kebutuhan, analisis ergonomi \& antrhopometri, analisis konfigurasi, analisis sistem, analisis material, analisis bentuk, analisis warna dan analisis produksi. Dari hasil analisis ini akan dihasilkan Spesifikasi desain produk.

4. Desain Alternatif. Berupa sketsa beberapa alternatif desain, yang akan dianalisis kelebihan dan kekurangannya, 
Dita Andansari, Hayde Starizky Dirgantara Girsang, Pengembangan Desain Sarana Memasak Makanan Ringan Portable

kemudian dipilih menjadi desain terpilih

yang akan dikembangkan.

5. Pengembangan Desain Alternatif Terpilih.

Yaitu pengembangan dari desain terpilih

tahap sebelumnya, menjadi desain final yang siap untuk diproduksi.

6. Desain Akhir. Yaitu finalisasi hasil desain yang bisa dibaca oleh tim produksi sehingga siap diproduksi menjadi produk jadi.

\section{Hasil dan Pembahsana}

Studi aktivitas dan kebutuhan dilakukan untuk mengetahui aktivitasaktivitas yang dilakukan berkaitan dengan produk yang akan dibuat sehingga diperoleh daftar kebutuhan pengguna. Berdasarkan kebutuhan tersebut maka dibuatlah pemecahan dalam memenuhi kebutuhan tersebut dan mengaplikasikannya pada produk. Adapun aktivitas yang dilakukan terlampir pada bagian lampiran existing studi aktivitas.

Berikut ini adalah tabel analisis aktivitas dan kebutuhan yang berkaitan dengan produk yaitu:

Tabel 1. Analisis aktivitas dan kebutuhan

\begin{tabular}{|l|l|}
\hline AKTIVITAS & KEBUTUHAN \\
\hline Menjinjing produk & Handle \\
\hline Memasak & $\begin{array}{l}\text { Wadah memasak, } \\
\text { Kompor dan tabung } \\
\text { gas portable }\end{array}$ \\
\hline Membuka dan menutup & Penutup \\
\hline Mengangkat makanan & Saringan makanan \\
\hline Mengunci kompor & Kuncian \\
\hline
\end{tabular}

Analisa ergonomi dilakukan untuk meminimalkan resiko kesehatan dan keselamatan dalam produk yang dirancang. Dengan begitu efisiensi, kesehatan, keselamatan, dan kenyamanan dalam melakukan kegiatan menggunakan produk dapat maksimal. Sedangkan analisa antropometri dilakukan guna mendapatkan dimensi atau ukuran produk yang sesuai dengan tubuh pengguna. Adapun unsur ergonomi yang ierhatikan yaitu:

1. Aktifitas membawa produk, adalah aktifitas yang penting dikarenakan aktifitas inilah yang sering dilakukan. Untuk aktifitas ini disediakan fasilitas handle atau pegangan yang ergonomis sehingga pengguna nyaman pada saat membawa produk dan beban angkat maksimum wanita tidak boleh lebih dari $16 \mathrm{~kg}$ sehingga pada saat pembawaan produk mengurangi rasa nyeri, ngilu pada tulang belakang.

2. Aktifitas membuka dan menutup, membutuhkan sebuah penutup. Aktifitas membawa produk membutuhkan sebuah handle atau pegangan, yang juga berfungsi pada saat membuka atau menutup produk. Penutup berfungsi juga menjaga dari percikan minyak dan menjaga hawa panas yang kemungkinan akan terjadi pada saat memasak juga menghindari makanan keluar pada saat memasakan seperti memasak popcorn, di sisi atas penutup juga terdapat lubanglubang agar uap yang akan terjadi pada saat memasak bisa keluar dan tidak terjadi gumpulan atau tetesan uap. 
Vol. 3, No. 2, April 2016

3. Untuk aktifitas pemanasan wadah memasak, disediakan kompor yang dianggap sesuai dengan konsep. Proses bakar dipilih yang mampu memanaskan hingga suhu yang sesuai. Wadah memasak juga dilengkapi dengan handle untuk mengangkat minyak yang dipakai setelah memasak. Handle menggunakan material yang tidak menghantarkan panas.

4. Aktifitas membalik makanan. Untuk membuat tingkat kematangan bahan makanan rotan disediakan penjepit makanan untuk melakukan pembalikan bertujuan untuk mengetahui sisi yang sudah matang selain itu juga bisa dijadikan sebagai pengangkat makanan yang telah matang.

5. Pada aktifitas mengangkat makanan, disediakan saringan untuk mengangkat makanan yang dimasak. Ditambah pada saringan makanan sebuah handle yang terbuat dari material yang tidak menghantarkan panas.

Analisis antropometri dilakukan guna mendapatkan dimensi atau ukuran produk yang sesuai dengan tubuh pemakai. Berdasarkan materi dari studi pustaka antropometri sebelumnya maka dilakukan analisis antropometri yang akan di aplikasikan pada produk agar sesuai dengan kenyamanan pengguna. Antropometri ini digunakan untuk mengetahui jarak antara produk dan lantai ketika membawa produk. Pada dimensi ini menggunakan 95 perentile dari wanita yaitu 690 mm. Maka Tinggi
Produk adalah d” 690 mm. berdasarkan analisis dan pertimbangan tinggi kompor dan panci $380 \mathrm{~mm}$, maka total tinggi sarana adalah $380 \mathrm{~mm}$

Analisis konfigurasi dilakukan guna mendapatkan tata letak dari tiap-tiap komponen yang terdapat pada produk ini. Adapun komponen yang harus diperhatikan dalam tata letak pada produk ini adalah: (1) lubang gas, (2) jendela transparan, (3) Penutup wadah kompor

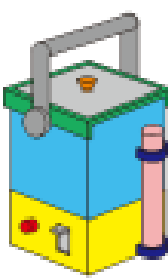

belakang

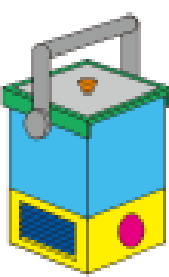

kiri

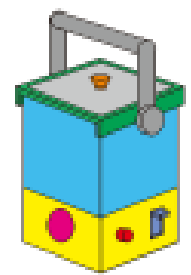

kanan

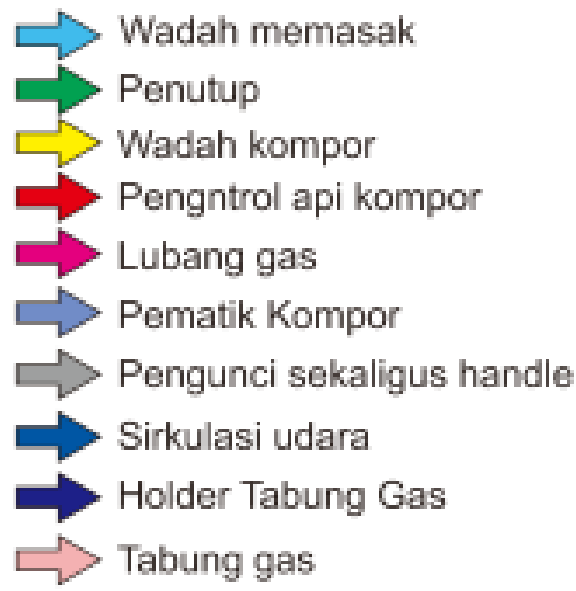

Gambar 1. Konfigurasi produk 
Dita Andansari, Hayde Starizky Dirgantara Girsang, Pengembangan Desain Sarana Memasak Makanan Ringan Portable

Setelah dilakukan analisis pada beberapa alternatif konfigurasi, terpilih Konfigurasi seperti yang ditunjukkan dalam gambar 1. Pada konfigurasi terpilih ini pada bagian tutup memiliki 1 jendela transparan yang berukuran besar dan berada tepat di tengah-tengah penutup, handle sekaligus pengunci tutup pada atas kompor, di bagian wadah kompor terdapat lubang gas berada di sisi depan, pematik dan pengontrol api pada kanan kompor, sirkulasi udara pada kiri kompor dan holder tabung gas pada belakang kompor.

Analisis sistem dilakukan guna menentukan sistem apa yang akan dipakai pada sarana memasak makanan ringan portabel sehingga akan memudahkan dalam aktivitas pengguna ketika akan menggunakan produk ini. Adapun sistem yang diaplikasikan adalah:

1. Sistem Sambungan Sekrup. Produk menggunakan sambungan sekrup dikarenakan ada bagian kompor yang semi permanen.

2. Sistem Kuncian. Analisis sistem dilakukan guna menentukan sistem apa yang akan dipakai pada pengembangan sarana memasak makanan ringan portabel ini sehingga akan memudahkan dalam aktivitas pengguna ketika akan menggunakan produk ini.

Kuncian kontainer arizona

Kuncian ini di ambil dari kontainer air minum arizona yang memiliki sistem kuncian sekaligus berfungsi sebagai handle untuk menjinjing kontainer ini. Kuncian ini cocok untuk mengunci bagian atas produk sarana memasak makanan ringan protabel.
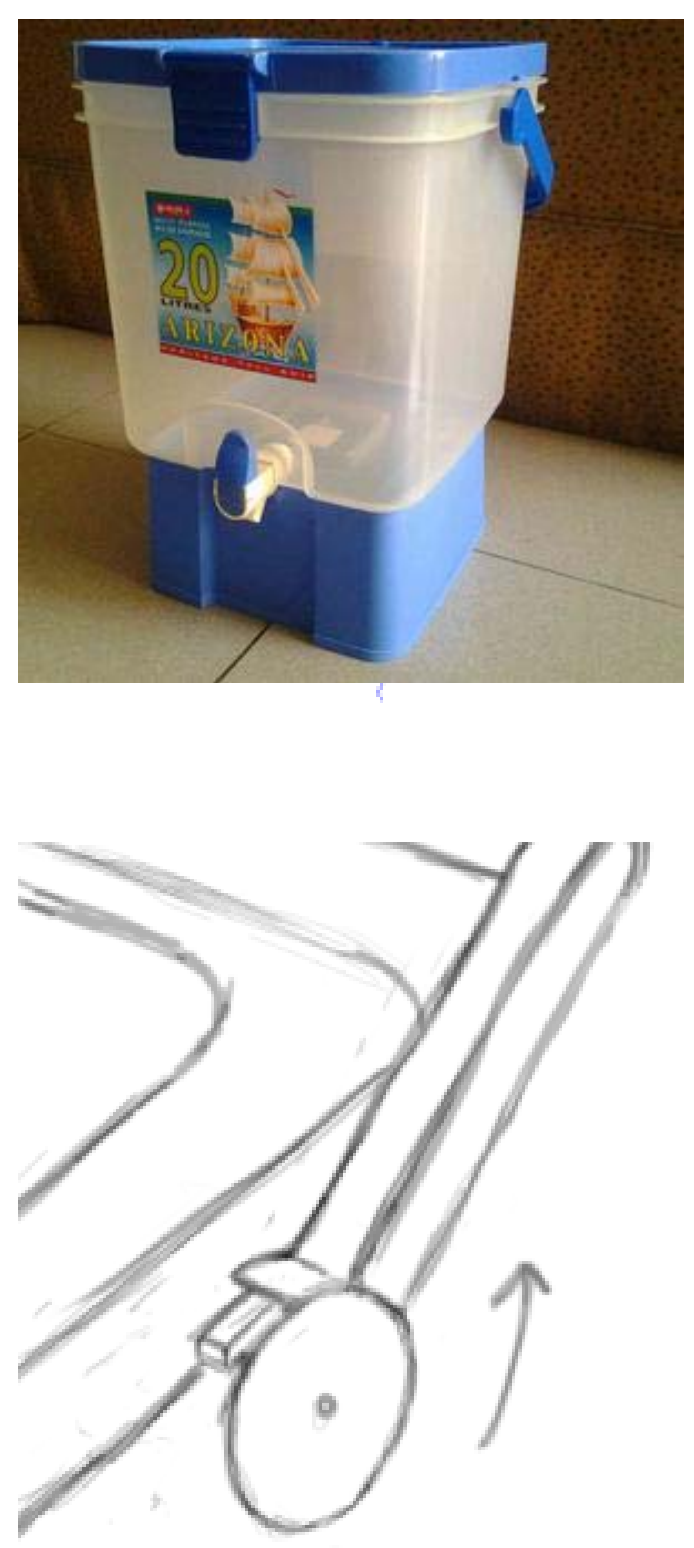

Gambar 2. Kuncian Arizona 
Vol. 3, No. 2, April 2016

Kuncian belender

Kuncian ini terdiri dari 2 bagian, bagian atas dan bagian bawah. Bagian atas belender memiliki bentuk yang menonjol keluar yang nantinya dipasangkan dengan belender bagian bawah dan kemudian putar sampai belender terkunci. Kuncian ini cocok untuk mengunci bagian tengah produk sarana memasak makanan ringan portabel.

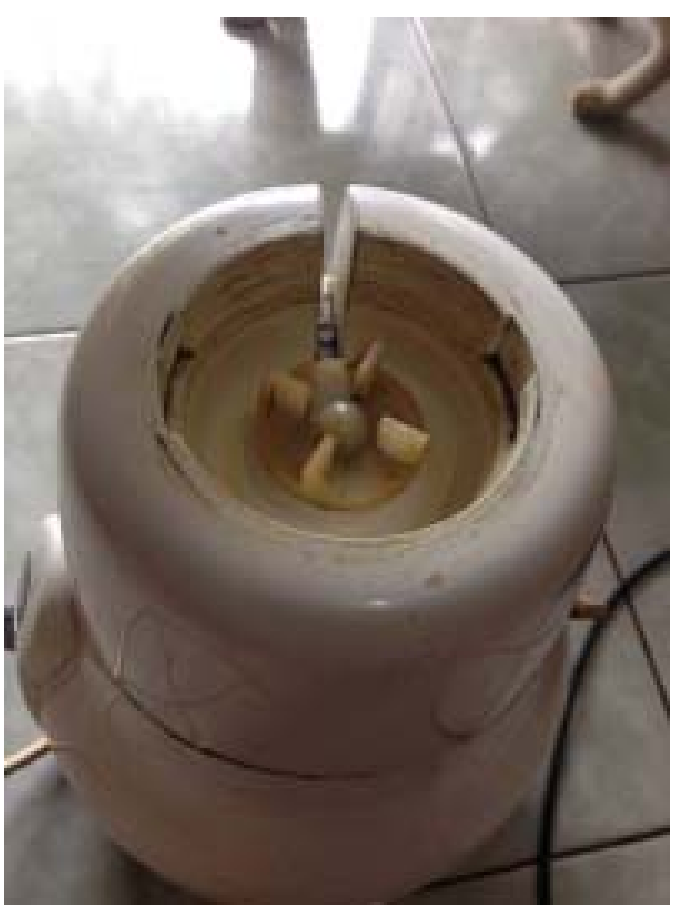

Gambar 3. Kuncian belender

Analisis material dilakukan untuk mengetahui material apa yang akan digunakan pada produk memasak ini. Dari analisis material yang telah dilakukan, nilai paling besar dihasilkan oleh material Aluminium dan Stainless steel, sehingga material inilah yang akan mendominasi produk yang akan dibuat.
Analisis bentuk diperlukan guna mendapatkan bentuk yang sesuai dengan konsep yang diambil. Bentuk desain yang digunakan adalah bentuk geometris, yaitu kotak, lingkaran, dan segitiga. Bentuk kotak ini dipilih karena memudahkan saat produksi, dan mengadopsi dari bentuk kentang goreng karena fungsi kompor ini yang dikhususkan untuk memasak cemilan itu.

Analisa warna diperlukan guna mendapatkan warna yang sesuai dengan konsep yang diambil. Dari analisis warna akromatik yang telah dilakukan, nilai paling besar dihasilkan oleh warna abu-abu dan hitam, dan ditambah Warna aksentuasi seperti warna cokelat yang akan diaplikasikan pada bagian handle dengan bahan kayu.

Setelah tahap analisis, selanjutnya tahap mendesain bentuk produk. Yang pertama dilakukan adalah dengan membuat sketsa-sketsa awal produk. Dari beberapa alternatif sketsa, dipilih sketsa yang memenuhi kriteria sebagai desain terpilih. Selanjutnya desain terpilih ini dikembangkan lagi menjadi beberapa desain pengembangan sesuai konsep dan kelayakan produksi, sehingga menjadi desain akhir. Desain final ini meliputi gambar presentasi, gambar tampak, gambar potongan, gambar urai, gambar detail, gambar isometri. Sehingga dengan desain final, produk bisa masuk tahap produksi untuk dibuat prototipe, yang akan dievalusi untuk diproduksi massal. 
Dita Andansari, Hayde Starizky Dirgantara Girsang, Pengembangan Desain Sarana Memasak Makanan Ringan Portable
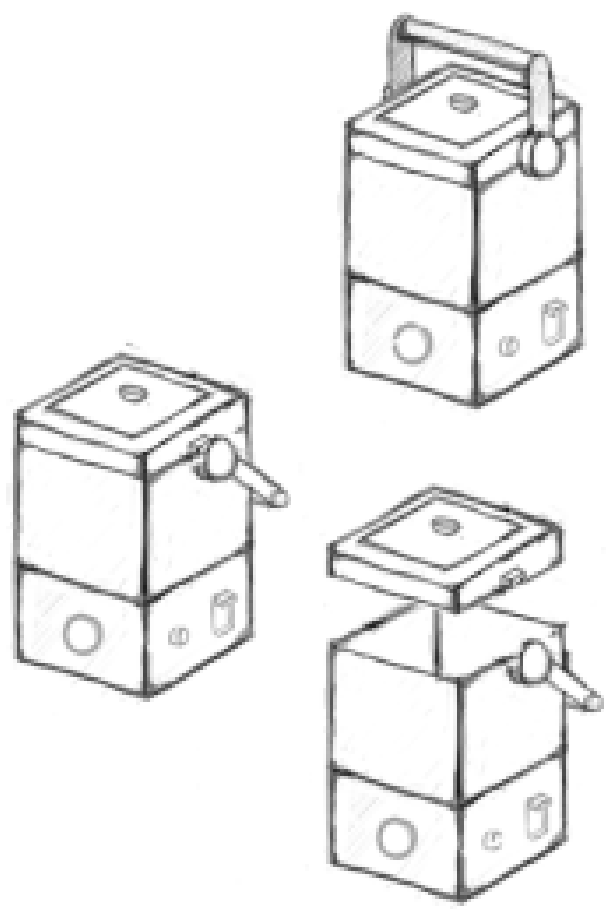

Gambar 4. Alternatif desain terpilih

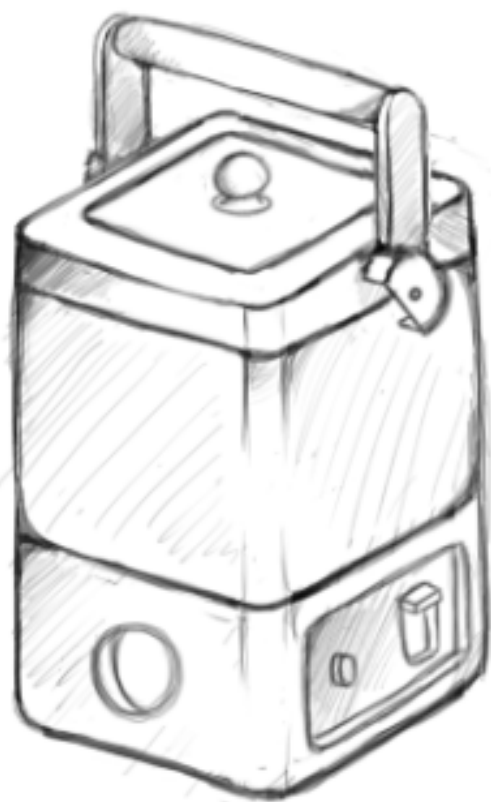

Gambar 5. Pengembangan desain terpilih

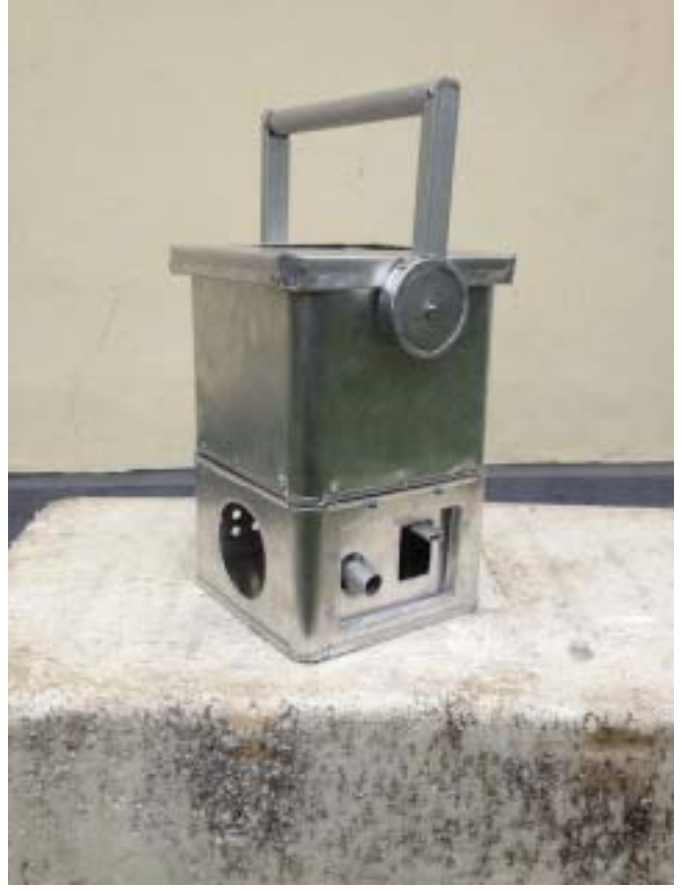

Gambar 6. Prototype produk

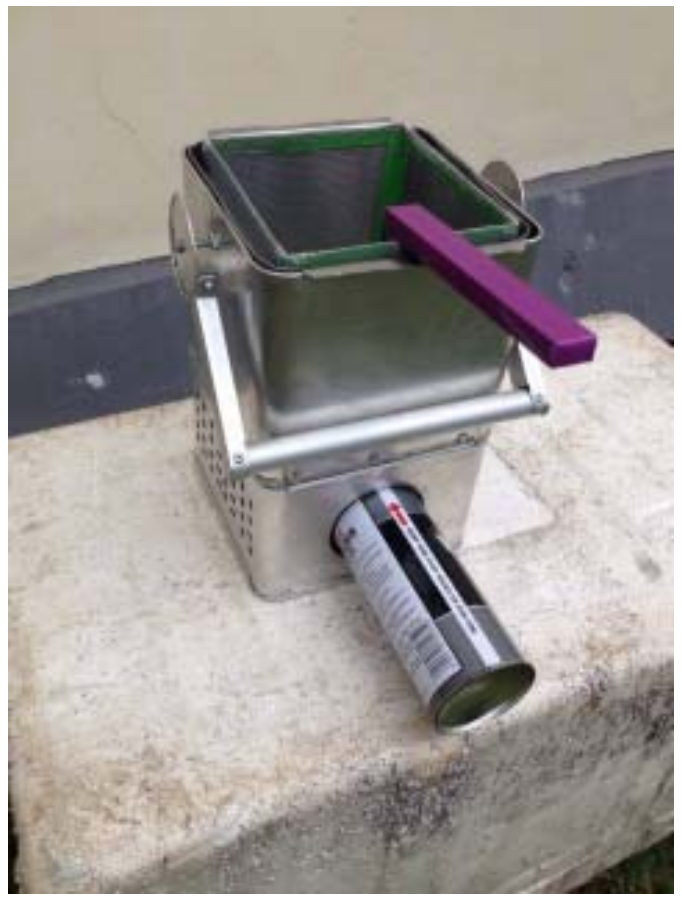

Gambar 7. Prototype produk 


\section{Kesimpulan}

Dari proses perancangan dan pengembangan alat membuat makanan ringan portabel hingga desain akhir yang dihasilkan adalah sebagai berikut: Alat pembuat makanan ringan portabel yang memiliki komponen yang lengkap dalam satu jinjingan untuk memasak memberikan kemudahan pada saat rekreasi sehingga mengurangi bawaan barang lainya. Alat pembuat makanan ringan portabel yang tidak menggunakan tenaga listrik untuk mengoprsikannya sehingga sesuai dengan konsep yang bisa di gunakan diluar ruangan ( outdoor ). Alat pembuat makanan ringan portabel yang didesain dari melihat permasalahan snack maker yang sudah beredar dan memperbaikinnya menambah jual beli tersendiri sebagai produk memasak. Saran yang dapat diberikan adalah jika produk ini ingin di produksi secara massal diadakan penelitian lebih lanjut tentang produk makanan khususnya snack maker dari segi material yang memiliki ketahanan terhadap tingkat kepanasan produk dari sistem proses memasak sampai ketahanan panas bodi produk. Selain itu material yang dipilih yang aman bagi makanan serta lingkungan, produk memiliki daya tahan yang kuat dan ringan agar mudah pada saat pembawaan produk sendiri. Pada saat proses produksi memiliki kualitas yang baik pada segi pembuatan produk maupun sistem-sistem yang di gunakan agar produk dapat digunakan dengan maksimal tanpa mengurangi keamanan dan kenyamanan memasak. Segi estetis dapat dilihat dari bagian bentuk C-Toves, warna, dan perpaduan material aluminium, stainlees, dan kayu. Dan masih memungkinkan untuk pengembangan dalam segi estetis. 
Dita Andansari, Hayde Starizky Dirgantara Girsang, Pengembangan Desain Sarana Memasak Makanan Ringan Portable

DAFTAR RUJUKAN

Ma’ruf, Hendri. 2006. Pemasaran Ritel. PT Gramedia Pustaka Utama. Jakarta.

R.A Hira Juwita , Andesita Oki K Form Follows Function

Rianur. 2013. Laporan Tugas Akhir: Sarana Memasak Makanan Ringan

Portabel.Samarinda

Suyanto. 2011. Analisis \& Desain Aplikasi Multimedia untuk Pemasaran

Widjajanta, Bambang; Widyaningsih, Aristanti; Tanuatmodjo, Heraeni. 2007. Ekonomi \& Akuntasi: Mengasah Kemampuan Ekonomi. Grasindo. Bandung.

Widjajanto, Bije. Cara Aman Memulai Bisnis. Grasindo

\section{WEBTOGRAFI}

http://www.wartawarga.gunadarma.ac.id (07/12/2010)

http://www.crayonpedia.org/mw/METODE_PENYAMBUNGAN._Ambiyar)(19/03/

2013)

https://www.scribd.com/doc/78476238/teknik-penyambungan (

http://www.petra.ac.id/ puslit/journals/dir.php?DepartmentID=INT) (08/12/2010)

http://srim.blog.stisitelkom.ac.id/2012/12/26/pengertian-kegiatan-outdoor/pengertian-

kegiatan-outdoor/ (06/03/2012)

(http://www.anneahira.com/makanan-ringan.htm, (06/04/2013)

http://chefkreasi.blogspot.com/p/pengertian-memasak.html) (06/03/2013)

http://digilib.petra.ac.id ( 13/12/2011)

http://elib.unikom.ac.id/files/disk1/523/jbptunikompp-gdl-dadangnugr-26103-3-

unikom d-2.pdf) (19/03/2013)

Http://pondokdaharlaukjogja.blogspot.com/2011/11/bahan-keramik-dalam- kehidupansehari.html ( 05/05/2012)

http://thinktep.wordpress.com/2009/05/27/komponen-desain- warna/) (05/04/2013) 